\title{
Aplicabilidade de Microrganismos Eficientes (ME) na Agricultura: uma revisão bibliográfica
}

\author{
Aplicability of Efficient Microorganisms (EM) in agriculture: literature review \\ Aplicabilidad de Microorganismos Eficientes (ME) en agricultura: revisión de la literatura
}

Recebido: 22/12/2021 | Revisado: 28/12/2021 | Aceito: 30/12/2021 | Publicado: 07/01/2022

\author{
André Lopes da Silva \\ ORCID: https://orcid.org/0000-0002-5193-2401 \\ Instituto Federal de Educação, Ciência e Tecnologia Baiano, Brasil \\ E-mail: lopes052017@gmail.com \\ Rogério Soares Cordeiro \\ ORCID: https://orcid.org/0000-0003-0682-3182 \\ Instituto Federal de Educação, Ciência e Tecnologia Baiano, Brasil \\ E-mail: rogerio.cordeiro@ifbaiano.edu.br \\ Heliselle Cristine Ramires da Rocha \\ ORCID: https://orcid.org/0000-0003-3200-3559 \\ Instituto Federal de Educação, Ciência e Tecnologia Baiano, Brasil \\ E-mail: heliselle.rocha@ifbaiano.edu.br
}

\begin{abstract}
Resumo
Um dos desafios do setor agropecuário é a produção de alimentos em maiores dimensões e com a menor geração de resíduos sólidos nas etapas da cadeia produtiva, uma vez que estes podem acarretar sérios danos ambientais e nos solos agricultáveis. No entanto, várias medidas podem ser adotadas, e aquilo que seria um problema, pode se tornar uma solução para o agricultor. A técnica da compostagem tem sido uma alternativa eficiente para o reaproveitamento dos resíduos tanto de origem animal como vegetal, que ao passarem pelo processo de decomposição, podem ser incorporados ao solo. Visando uma maior aceleração e estabilização destes resíduos, tem se empregado a adição de Microrganismos Eficientes (MEs). Além de serem atuantes na decomposição, os MEs favorecem a disponibilização dos nutrientes e minerais do solo às plantas de forma eficaz. Deste modo, neste estudo realizou-se um levantamento bibliográfico sobre a produção acadêmica brasileira, no que se refere aos MEs. E, de forma mais específica, categorizar os diferentes manuscritos, a partir de critérios como o potencial biológico na agricultura e os diferentes tipos de substratos, onde MEs foram analisados. Com base nos resultados encontrados nessa revisão, conclui-se que os MEs possuem uma ampla utilização e benefícios para o desenvolvimento sustentável da agricultura. Percebe-se também, que diversas pesquisas comprovam as suas vantagens no processo de produção de substratos através do tratamento de resíduos com uso das técnicas de compostagem e vermicompostagem, possibilitando a reinserção dos mesmos nos solos cultiváveis, contribuindo com a melhoria das suas condições físico-químicas e biológicas.
\end{abstract}

Palavras-chave: Ciclagem de nutrientes; Resíduos; Compostagem; Sustentabilidade.

\begin{abstract}
One of the challenges of the agriculture sector is the production of food in larger dimensions and with less generation of solid residues in the stages of the production chain, since these can cause serious environmental and agricultural soil damage. However, several measures can be adopted, and what would be a problem, can become a solution for the farmer. The composting technique has been an efficient alternative for the reuse of residues of both animal and vegetable origin, which, when going through the decomposition process, can be incorporated into the soil. Aiming at a greater acceleration and stabilization of these residues, the addition of Efficient Microorganisms (EMs) has been used. In addition to being used in decomposition, the MEs favor the availability of soil nutrients and minerals to plants effectively. Thus, this study conducted a bibliographic survey on Brazilian academic production, with regard to MEs. And, more specifically, categorize the different manuscripts, based on criteria such as the biological potential in agriculture and the different types of substrates, where MEs were analyzed. Based on the results found in this review, it is concluded that MEs have a wide use and benefits for the sustainable development of agriculture. It is also noticed that several researches prove its advantages in the process of substrate production through the treatment of residues with the use of composting and vermicomposting techniques, enabling their reintegration into arable soils, contributing to the improvement of their physical-chemical and biological conditions.
\end{abstract}

Keywords: Nutrient cycling; Residues; Composting; Sustainability. 


\begin{abstract}
Resumen
Uno de los desafíos del sector agropecuario es la producción de alimentos en mayores dimensiones y con menor generación de residuos sólidos en las etapas de la cadena productiva, ya que estos pueden causar serios daños al medio ambiente y suelos agrícolas. Sin embargo, se pueden adoptar varias medidas y lo que sería un problema, puede convertirse en una solución para el agricultor. La técnica del compostaje ha sido una alternativa eficaz para la reutilización de residuos tanto de origen animal como vegetal, que, al pasar por el proceso de descomposición, pueden incorporarse al suelo. Con el objetivo de una mayor aceleración y estabilización de estos residuos, se ha utilizado la adición de Microorganismos Eficientes (EM). Además de ser activos en descomposición, los ME favorecen la disponibilidad de nutrientes y minerales del suelo para las plantas de manera efectiva. Así, en este estudio se realizó un relevamiento bibliográfico sobre la producción académica brasileña, en relación a los EM. Y, más concretamente, categorizar los diferentes manuscritos, en base a criterios como el potencial biológico en agricultura y los diferentes tipos de sustratos, donde se analizaron las EM. Con base en los resultados encontrados en esta revisión, se concluye que las EM tienen un amplio uso y beneficios para el desarrollo sostenible de la agricultura. También se advierte que diversas investigaciones demuestran sus ventajas en el proceso de producción de sustratos mediante el tratamiento de residuos con el uso de técnicas de compostaje y vermicompostaje, permitiendo su reinserción en suelos arables, contribuyendo a la mejora de sus condiciones físicas químicas y biológicas.
\end{abstract}

Palabras clave: Ciclo de nutrientes; Desperdicio; Compostaje; Sustentabilidad.

\title{
1. Introdução
}

Um dos grandes desafios dos setores agropecuários na atualidade é a produção de alimentos em maiores dimensões e com a menor geração de resíduos nas etapas da cadeia produtiva. As questões ambientais têm provocado, cada vez mais, preocupação de todos que convivem e se envolvem com as atividades agrícolas, uma vez que os resíduos gerados podem acarretar sérios danos ambientais nestas áreas, como a diminuição da produtividade das lavouras ou até mesmo a desertificação dos solos agricultáveis.

No entanto, várias medidas podem ser adotadas nos setores de produção e, aquilo que seria um problema, pode se tornar uma solução para o agricultor. Um exemplo é o gerenciamento eficaz dos resíduos sólidos, destinando-os para utilização em uma nova cadeia de produção.

A técnica da compostagem tem sido amplamente utilizada nos setores agropecuários, tendo em vista como uma alternativa eficiente para o reaproveitamento dos resíduos tanto de origem animal como vegetal, que ao passarem pelo processo de decomposição, podem ser incorporados ao solo, proporcionado melhorias em suas características físicas, físicoquímicas e biológicas.

Uma das estratégias utilizadas para acelerar a degradação, estabilização e humificação destes resíduos são os Microrganismos Eficientes, que serão referidos, no presente estudo, como 'MEs'. Trata-se de comunidades de microrganismos (leveduras, actinomicetos, bactérias produtoras de ácido lático e bactérias fotossintetizantes) encontrados naturalmente em solos férteis e em plantas que coexistem em meio líquido.

$\mathrm{Na}$ literatura é possível verificar alguns experimentos já realizados comprovando que os processos de compostagem podem ser otimizados com a adição dos MEs. Goes et al. (2017) aplicaram na compostagem de resíduo agroindustrial e poda de árvore; Caetano (2014) avaliou diferentes concentrações no processo de compostagem da palha de cana-de-açúcar e esterco bovino.

Neste mesmo sentido, Máximo (2018) trabalhou com compostagem de resíduos sólidos agroindustriais utilizando-os para a aceleração do processo; Caetano et al. (2020) avaliaram a decomposição de resíduos de soja e milho, e Muscope (2017) analisou compostagens de resíduos agroindustriais inoculadas com microrganismos eficientes.

Ante ao exposto, o objetivo geral do presente trabalho foi realizar um levantamento bibliográfico sobre a produção acadêmica brasileira, no que se refere aos 'MEs'. E, de forma mais específica, categorizar os diferentes manuscritos, a partir de critérios como o potencial biológico na agricultura e os diferentes tipos de substratos, onde MEs foram analisados. 


\section{Metodologia}

Esta pesquisa possui natureza mista, definida por Minayo (2012) com um entremeio científico, alinhando dados quantitativos com explicações qualitativas. Dessa forma, assumem-se, nesta produção, as duas abordagens como complementares.

A pesquisa quantitativa, tanto pretende, quanto permite a determinação de indicadores e tendências presentes na realidade, ou seja, dados representativos e objetivos, cujo eixo central deste tipo de análise é a materialização físico-numérica na explicação (Mussi et al., 2019). Aspectos que reforçam o caráter estatístico, diante da sua potencialidade na análise de dados e possibilidade de inferência, pedindo apenas o respeito à variabilidade aleatória amostral (Minayo \& Sanches, 1993). A capacidade de generalização é sua principal característica, o acontecido na amostra será assumido para a população, que não precisa ter sido estudada integralmente (Mussi et al., 2019).

Abordagens qualitativas se desenvolveram paralelamente às quantitativas, focando sua atenção na indução, nos mecanismos subjacentes aos comportamentos e as interpretações destes pelos próprios sujeitos, valorizando a diversidade (Alami et al., 2010).

Para além da abordagem mista, este trabalho caracteriza-se como um estudo descritivo, realizado por meio da pesquisa documental (Gil, 2010). Esse tipo de análise tem os documentos como fonte natural e poderosa de informações, sob a natureza de determinados contextos (Lüdke \& André, 2015).

As pesquisas descritivas bibliográficas são aquelas que objetivam investigar determinadas características de uma população ou de certo fenômeno a partir de material já elaborado, principalmente, em livros e artigos (Gil, 2002). Na presente análise, artigos científicos, boletins técnicos, monografias, dissertações e teses, especificamente.

Assim, o universo de artigos inclusos na análise obedeceu a uma sequência rigorosa de busca, a começar pela seleção das palavras-chave. As expressões, "Microrganismos eficientes na agricultura", "Microrganismos eficientes no Cultivo", "Aplicação de Microrganismos eficientes", "Utilização de Microrganismos eficientes", "Microrganismos eficientes no solo", "Microrganismos eficientes na compostagem", "Microrganismos eficientes na decomposição", "Efeito dos Microrganismos eficientes", "Inoculação de microrganismos eficientes", "Dosagens de EM" e "Concentrações de Micro-organismos Eficientes" foram exclusivamente utilizadas. Esta etapa da pesquisa foi organizada da seguinte forma:

a) acesso à base de dados do Google Acadêmico realizando a busca de trabalhos a partir do descritor "Microrganismos Eficientes" e aplicação dos filtros de pesquisa: allintitle, não inclusão de citações e publicação até o ano de 2008.

b) Download dos trabalhos e arquivamento em uma pasta de computador adequadamente nomeada;

c) leitura seletiva dos artigos armazenados com a extração de dados dos trabalhos com base em categorias definidas a priori - ano, local da publicação, autores, título, palavras-chave e resumo;

d) Categorização da aplicação dos microrganismos eficientes em relação a sua utilização na agricultura, no solo e na decomposição de resíduos utilizando o processo da compostagem.

Após seleção das publicações, realizou-se uma leitura e a partir desta foi feita uma nova seleção, descartando aquelas que não se enquadram no contexto a ser trabalhado nesta proposta. A partir da leitura dos trabalhos selecionados, verificou-se a necessidade de incluir os trabalhos de Bonfim et al (2011) e Andrade (2020), os quais são citados na maioria das publicações, e de fundamental importância no eixo temático desta pesquisa. Assim sendo, as mesmas foram obtidas a partir de uma pesquisa manual com base no observado das referências dos trabalhos citados. Com os trabalhos selecionados, foi feito a organização das ideias em subtemas que englobam a utilização dos EM e seus benefícios no ramo agrícola. 


\section{Resultados e Discussão}

O universo de artigos científicos, boletins técnicos, monografias, dissertações e teses inclusas nesta pesquisa, compreendeu o total de trabalhos encontrados no portal Google Acadêmico, onde a expressão "Microrganismos Eficientes" ocorresse no título, palavras-chave ou resumo dos estudos, sendo 25 o total de trabalhos que compõem a amostra. Para todos os casos, foi feita a exclusão de entradas apenas do tipo citação (Quadro 1).

Quadro 1. Publicações relacionadas à pesquisa.

\begin{tabular}{|c|c|c|c|c|}
\hline Indexador & Autor(es) & Ano & Título & Palavras-chave \\
\hline Google Acadêmico & Goes et al. & 2017 & $\begin{array}{l}\text { Compostagem de resíduo agroindustrial e poda } \\
\text { de árvore com aplicação de microrganismos } \\
\text { eficientes }\end{array}$ & $\begin{array}{l}\text { Composto orgânico, Resíduos de } \\
\text { laticínios, Tratamento de resíduos } \\
\text { sólidos agroindustriais. }\end{array}$ \\
\hline Google Acadêmico & Máximo & 2018 & $\begin{array}{l}\text { Inoculação de microrganismos como } \\
\text { aceleradores no processo de compostagem de } \\
\text { resíduos sólidos agroindustriais }\end{array}$ & $\begin{array}{c}\text { Compostagem, Inoculação de } \\
\text { microrganismos, Microrganismos } \\
\text { eficazes, Lodo, Película prateada } \\
\text { do café, Resíduo ruminal, } \\
\text { Resíduos agroindustriais. }\end{array}$ \\
\hline Google Acadêmico & Avila et al. & 2021 & Use of efficient microorganisms in agriculture & $\begin{array}{l}\text { Isolation, Multiplication, Storage, } \\
\text { Sustainability. }\end{array}$ \\
\hline Google & Bonfim et al. & 2011 & $\begin{array}{l}\text { Caderno dos Microrganismos Eficientes (EM) } \\
\text { Instruções práticas sobre uso ecológico e social } \\
\text { do EM }\end{array}$ & -- \\
\hline Google Acadêmico & Caetano & 2014 & $\begin{array}{l}\text { Micro-organismos eficentes (EM's) na } \\
\text { compostagem de palha de cana-de-açúcar e } \\
\text { esterco bovino }\end{array}$ & $\begin{array}{l}\text { Resíduos sólidos, Reator de } \\
\text { bancada, Físico-químico, } \\
\text { Microbiológico. }\end{array}$ \\
\hline Google & Andrade & 2020 & $\begin{array}{l}\text { Caderno dos microrganismos eficientes (E.M.) } \\
\text { Instruções práticas sobre uso ecológico e social } \\
\text { do EM }\end{array}$ & -- \\
\hline Google Acadêmico & Pugas et al. & 2013 & $\begin{array}{l}\text { Efeito dos Microrganismos Eficientes na taxa } \\
\text { germinação e no crescimento da Abobrinha } \\
\text { (Curcubita Pepo L.) }\end{array}$ & $\begin{array}{l}\text { Microrganismos eficazes, } \\
\text { Abobrinha, Curcubita Pepo L. }\end{array}$ \\
\hline Google Acadêmico & Panisson & 2017 & $\begin{array}{l}\text { Avaliação de diferentes processos de } \\
\text { compostagem em pequena escala com adição de } \\
\text { microrganismos eficientes }\end{array}$ & $\begin{array}{l}\text { Compostagem, } \\
\text { vermicompostagem, } \\
\text { Microrganismos eficientes, } \\
\text { Pequena escala. }\end{array}$ \\
\hline Google Acadêmico & $\begin{array}{l}\text { Sousa; Pontes } \\
\& \text { Melo. }\end{array}$ & 2020 & Efficient Microorganisms in lettuce cultivation & $\begin{array}{l}\text { Lactuca sativa, Organic } \\
\text { production, Biological cocktail. }\end{array}$ \\
\hline Google Acadêmico & $\begin{array}{l}\text { Vicentini; } \\
\text { Carvalho \& } \\
\text { Richter. }\end{array}$ & 2009 & $\begin{array}{l}\text { Utilização de Microorganismos Eficazes no } \\
\text { Preparo da Compostagem }\end{array}$ & $\begin{array}{l}\text { Adubação orgânica, Dejetos } \\
\text { animais, Resíduos, Esterco ovino } \\
\text { e bovino. }\end{array}$ \\
\hline Google Acadêmico & Dourado & 2018 & $\begin{array}{l}\text { Microrganismos eficientes (EM) no tratamento } \\
\text { de sementes de milho }\end{array}$ & -- \\
\hline Google Acadêmico & Conceição & 2012 & $\begin{array}{l}\text { Coquetel biológico (EM) no crescimento de } \\
\text { mudas de Ocimum basilicum L. }\end{array}$ & $\begin{array}{l}\text { Composto biológico, Manjericão, } \\
\text { Microbiologia do solo. }\end{array}$ \\
\hline Google Acadêmico & Higa \& Paar. & 2013 & $\begin{array}{l}\text { Microorganismos Benéficos y efectivos para una } \\
\text { agricultura y medio ambiente sostenibles }\end{array}$ & -- \\
\hline Google Acadêmico & Mares Guia & 2018 & $\begin{array}{l}\text { Produtividade de Milho Verde Cultivado em } \\
\text { Sucessão a Adubação Verde com Aplicação de } \\
\text { Microrganismos eficientes, nas Condições de } \\
\text { Matias Barbosa, MG }\end{array}$ & $\begin{array}{l}\text { Agroecologia, Sistemas de } \\
\text { Cultivo, Extensão Rural. }\end{array}$ \\
\hline Google Acadêmico & Silva et al. & 2020 & $\begin{array}{l}\text { Produção de pimentão em ambiente protegido } \\
\text { sob diferentes concentrações de microrganismos } \\
\text { eficientes }\end{array}$ & $\begin{array}{l}\text { Capsicum annuum, Orgânico, } \\
\text { Sistema protegido. }\end{array}$ \\
\hline Google Acadêmico & Mwegoha & 2012 & $\begin{array}{l}\text { Compostagem anaeróbica de resíduos de piretro } \\
\text { com e sem microorganismos eficazes }\end{array}$ & $\begin{array}{c}\text { Biogás, Compostagem, } \\
\text { Microorganismos eficazes (EM), } \\
\text { Metano, Bagaço. }\end{array}$ \\
\hline Google Acadêmico & Pereira et al. & 2014 & $\begin{array}{l}\text { Utilização de Microrganismos eficientes (EM) na } \\
\text { produção de alimentos orgânicos }\end{array}$ & $\begin{array}{l}\text { Agroecologia, Insumos, } \\
\text { Agricultura natural. }\end{array}$ \\
\hline Google Acadêmico & Caetano et al. & 2020 & $\begin{array}{l}\text { Microrganismos eficientes na decomposição de } \\
\text { resíduos de soja e milho }\end{array}$ & $\begin{array}{l}\text { Ciclagem de Nutrientes, } \\
\text { Microrganismos Eficientes, } \\
\text { Resíduos Vegetais. } \\
\end{array}$ \\
\hline Google Acadêmico & Grazik & 2020 & $\begin{array}{l}\text { Tratamento de resíduos orgânicos agroindustriais } \\
\text { por Vermicompostagem em pequena escala }\end{array}$ & $\begin{array}{l}\text { Microrganismos Eficientes, } \\
\text { Patógenos, Temperatura, } \\
\text { Micronutrientes, } \\
\text { Macronutrientes, Metais. }\end{array}$ \\
\hline Google Acadêmico & Pedrosa et al. & 2015 & $\begin{array}{l}\text { Importância ecológica dos microrganismos do } \\
\text { solo }\end{array}$ & $\begin{array}{l}\text { Biomassa microbiana, } \\
\text { Crescimento de plantas, } \\
\text { Micorrizas, Microrganismos } \\
\text { eficazes. }\end{array}$ \\
\hline
\end{tabular}




\begin{tabular}{|c|c|c|c|c|}
\hline Google Acadêmico & Muscope & 2017 & $\begin{array}{l}\text { Compostagem de resíduos agroindustriais através } \\
\text { da Inoculação de microrganismos eficientes: } \\
\text { Uma alternativa para a compostagem em } \\
\text { pequena escala }\end{array}$ & $\begin{array}{l}\text { Pequena escala, Temperatura, } \\
\text { Microrganismos patogênicos, } \\
\text { Macronutrientes. }\end{array}$ \\
\hline Google Acadêmico & $\begin{array}{l}\text { Calero-Hurtado } \\
\text { et al. }\end{array}$ & 2019 & $\begin{array}{l}\text { Efecto entre microorganismos eficientes y } \\
\text { fitomas-e en el incremento agroproductivo del } \\
\text { frijol }\end{array}$ & $\begin{array}{c}\text { Aplicación foliar, Bioproductos, } \\
\text { Época de siembra, Phaseolus } \\
\text { vulgaris, Productividad. }\end{array}$ \\
\hline Google Acadêmico & $\begin{array}{l}\text { Alvarez-Vera } \\
\text { et al. }\end{array}$ & 2019 & $\begin{array}{l}\text { Obtención de consorcios microbianos benéficos y } \\
\text { su incidencia en la población microbiana nativa } \\
\text { de la rizósfera de plantas de fresa (Fragaria sp.) }\end{array}$ & $\begin{array}{c}\text { Microorganismos benéficos, } \\
\text { Suelo, Raíz, Plantas, } \\
\text { Antagonismo. }\end{array}$ \\
\hline Google Acadêmico & Fan et al. & 2018 & $\begin{array}{l}\text { Evaluation of Effective Microorganisms on } \\
\text { Home Scale Organic Waste Composting }\end{array}$ & $\begin{array}{c}\text { Effective Microorganisms, Food } \\
\text { and organic waste composting, } \\
\text { Home scale, Nutrient content, } \\
\text { Humic acid. }\end{array}$ \\
\hline Google Acadêmico & $\begin{array}{l}\text { Cargnelutti et } \\
\text { al. }\end{array}$ & 2021 & $\begin{array}{l}\text { Soluções tecnológicas emergentes para uma } \\
\begin{array}{l}\text { agricultura } \\
\text { eficientes }\end{array} \\
\text { sustentável: }\end{array}$ & $\begin{array}{l}\text { Agroecologia, Crescimento de } \\
\text { plantas, Fisiologia, } \\
\text { Microrganismos eficientes. }\end{array}$ \\
\hline
\end{tabular}

Fonte: Autores (2021).

A partir da leitura seletiva dos artigos armazenados, uma análise minuciosa dos títulos, resumos e palavras-chave, foi possível estabelecer a proposição de categorias, a fim de se ter clareza, das principais tendências de publicações, no que tange à temática proposta. Assim, foram propostas três categorias, a saber: 1) Agricultura; 2) Solo e 3) Compostagem e Resíduos com Potencial para utilização no processo de compostagem com a adição dos MEs (Quadro 2). Além disso, a partir de uma leitura aprofundada, foi possível categorizar os resíduos que apresentaram potencial no processo de compostagem com a utilização dos Microrganismos Eficientes.

Quadro 2. Publicações de acordo com as categorias relacionadas à pesquisa.

\begin{tabular}{|c|c|c|}
\hline Categorias & Trabalhos encontrados & Trabalhos utilizados \\
\hline Agricultura & 43 & 12 \\
\hline Solo & 33 & 7 \\
\hline Compostagem e Resíduos com Potencial & 26 & 11 \\
\hline Total & 102 & 30 \\
\hline
\end{tabular}

Fonte: Autores (2021).

Alguns dos trabalhos utilizados na pesquisa apareceram em mais de uma das categorias, isso por tratarem de temas mais complexos e que envolvem maior amplitude do estudo da arte. Neste sentido, eles foram utilizados em diferentes categorias.

\subsection{Uso de Microrganismos Eficientes (MEs) na Agricultura}

Nas atividades agrícolas de base ecológica, busca-se utilizar de tecnologias que baseiam na agricultura natural, com máximo proveito da natureza, das ações do solo, dos organismos vivos, da energia solar e dos recursos hídricos. Os microrganismos que atuam de forma benéfica na agricultura também são conhecidos como Microrganismos Eficientes os quais são encontrados naturalmente no ambiente, mas que podem ser adicionados ao sistema visando o aumento da diversidade microbiana do mesmo (Caetano, 2014).

Segundo Pugas et al. (2013), a adição de MEs ao solo contribui significativamente para o aumento da diversidade microbiológica, atuando como indutores da decomposição da matéria orgânica e por consequência na disponibilização dos nutrientes às plantas, tornando estas mais resistentes ao ataque de patógenos, os quais poderiam comprometer a produtividade da cultura. De modo geral, a utilização de MEs favorece e beneficia os agricultores e o cultivo de diversas culturas, dentre as quais, Calero-Hurtado et al. (2019) destacam estudos com hortaliças, milho e feijão. 
De acordo com Avila et al. (2021), as diferentes espécies que integram o grupo dos microrganismos eficientes produzem ácidos orgânicos, hormônios vegetais (giberelinas, auxinas e citocininas), além de vitaminas, antibióticos e polissacarídeos, tais produtos influenciam positivamente no desenvolvimento das plantas de forma direta ou indireta. Bonfim et al. (2011) destacam inúmeros benefícios relacionados ao uso dos MEs, por se tratar de uma tecnologia econômica e natural, segura, fácil de usar e de alta qualidade, além de ser uma fonte alternativa de renda com a produção de biogás, composto orgânico e biofertilizantes.

Nos processos distintos de sistemas de produção agrícola, os MEs podem contribuir de forma efetiva para a melhoria e aprimoramento das técnicas agrícolas de produção, reduzindo assim, os impactos ambientais negativos provocados pela agricultura possibilitando: a manutenção de sistemas limpos, a produção de alimentos saudáveis, assim como, equilibrados nutricionalmente e livres de resíduos químicos (Bonfim et al., 2011).

Vicentini et al. (2009) relataram que, ao adicionar os MEs no preparo da compostagem, houve a diminuição da ocorrência de fortes odores no composto, aumentando a eficiência e maior rapidez no processo de fermentação, além de garantir uma maior concentração de nutrientes. Por isso, sua utilização na agricultura natural objetiva a decomposição da matéria orgânica e a disponibilização dos nutrientes e minerais do solo às plantas de forma eficiente (Dourado, 2018).

Visando a melhoria da sanidade em sementes de milho, Dourado (2018) testou diferentes concentrações de MEs, via tratamento de sementes, provindos de três origens distintas (comercial e de agricultores familiares). Os resultados foram satisfatórios para todos os tratamentos com MEs sem diluição, independente da origem, promovendo redução de $21 \%$ a $67 \%$ na incidência dos fungos patogênicos avaliados.

Sousa et al. (2020), avaliando a eficiência da aplicação de um coquetel biológico proveniente de Microrganismos Eficientes no cultivo de alface americana, concluíram que as plantas submetidas a este produto obtiveram um maior aumento na biomassa da parte aérea, resultando em uma maior produtividade da cultura. Neste sentido, os MEs podem ser utilizados para favorecer o despenho no cultivo de alface, destacando-se como uma técnica agroecológica e sustentável na produção.

Silva et al. (2020), analisando o efeito de diferentes concentrações de MEs na produção de pimentão sob sistema de cultivo protegido no município de Cruzeiro do Sul - Acre, constataram por meio da análise de regressão que o ponto máximo de produção ocorreu na dosagem de 8,96 ml/parcela do concentrado de MEs. Assim, a produção de pimentão foi influenciada positivamente com a adição dos MEs no sistema de cultivo estudado.

Ao analisarem o efeito de diferentes doses de microrganismos eficazes na germinação, emergência, crescimento e qualidade de mudas de manjericão (Ocimum basilicum), Conceição et al. (2012) concluíram que os MEs influenciam positivamente no desenvolvimento das mudas, a dosagem de $30 \mathrm{ml}$ proporcionou melhores resultados na emergência e no crescimento do manjericão.

Andrade (2020) destaca os resultados positivos quando os MEs foram associados às técnicas de cultivo orgânico, como a adubação verde, biofertilizante e compostagem atreladas ao bom manejo conservacionista do solo, consorciação e rotação de culturas.

Desse modo, a utilização de MEs traz a possibilidade de alcançar níveis econômicos máximos e alta qualidade, maior retorno líquido, sem a aplicação de fertilizantes químicos, pesticidas e métodos agrícolas convencionais, conservando os recursos naturais e criando uma agricultura e meio ambiente mais sustentáveis (Higa \& Paar, 2013). Além de serem adequados ao ambiente também são à saúde humana, aproximando-se da agricultura natural, uma vez que sua utilização visa a busca pelo máximo aproveito da natureza (Andrade, 2020). 


\subsection{Uso de Microrganismos Eficientes (MEs) nos Solos}

A composição biológica do solo, constituída por diversos grupos de microrganimos que agem sobre a matéria orgânica do solo, no desenvolvimento permanente dos processos de síntese e análise dos compostos orgânicos, faz com que o solo seja considerado uma entidade biológica (Pedrosa et al., 2015).

Dentre a fração biológica presentes no solo estão os Microrganismos Eficientes (ME). Estes são encontrados, naturalmente, em solos não degradados, férteis e com plantas (Mares Guia, 2018). São altamente eficientes e pertencem ao grupo dos microrganismos regenerativos, os quais possuem a capacidade de produzir substâncias orgânicas que melhoram as condições estruturais e mineralógicas dos solos.

Alvarez-Vera et al. (2019) destacam que a população microbiana nativa da rizosfera, que estão adaptadas com as circunstâncias locais, tende a aumentar fundamentalmente devidos às condições propícias ao seu desenvolvimento existentes na zona de crescimento das raízes, na qual obtêm os nutrientes necessários ao seu sustento.

De acordo com Cargnelutti et al. (2021) os MEs são agentes benéficos, tanto para as plantas quanto para o solo, pois promovem a melhoria da sua qualidade estrutural e a saúde das plantas, de modo a se tornar uma ferramenta indispensável na potencialização da ciclagem de nutrientes e no favorecimento dos processos naturais dos ecossistemas de uma propriedade.

Efetuam, coletivamente, a transformação da matéria orgânica do solo, contribuindo para a manutenção da microvida, a saúde e o equilíbrio do ambiente deste solo, ao atuarem na agregação, qualidade e sanidade do solo, manutenção dos poros, liberação dos nutrientes, fixação de nitrogênio e produção de substâncias protetoras das plantas (Mares Guia, 2018).

Bonfim et al. (2011) afirmam que os MEs realizam um trabalho importantíssimo, equilibrando o ambiente do solo, controlando os microrganismos nocivos e proporcionando um solo mais favorável a produção agrícola. Os autores também apresentam várias vantagens na utilização destes, destacando a recomposição da microbiota saudável do solo; a restauração das propriedades físico-químicas e microbiológicas; o estímulo à emergência das plantas, facilitando o manejo e a cobertura do solo, a diminuição de doenças e patógenos do solo, decomposição de matéria orgânica, mineralização e disponibilização de nutrientes essenciais, dentre outras vantagens.

Silva et al. (2021) salientam que a presença de MEs torna o solo mais rico em energia vital, tornando plena a capacidade natural de produção do solo. Com isso, acrescentam a melhoria no metabolismo das plantas, da capacidade fotossintética, do crescimento radicular, florescimento, frutificação e maturidade de grãos e frutos (Andrade, 2020).

Enfim, a utilização de Microrganismos Eficientes tem sido uma alternativa para a substituição de fertilizantes sintéticos no suprimento nutricional de cultivos em sistemas orgânicos, uma vez que estes contribuem com o fortalecimento natural do solo (Bonfim et al., 2011) e reduzem os custos com adubação mineral.

\subsection{Uso de Microrganismos Eficientes (MEs) no processo de compostagem}

$\mathrm{O}$ aumento do poder de aquisição da população viabiliza um maior consumo de bens e produtos. Isto eleva a demanda, levando a um aumento de produção das indústrias, comércio e agropecuário. Consequentemente, há uma maior geração de resíduos nas cadeias produtivas que, se não receberem um gerenciamento adequado, pode impactar negativamente o meio ambiente (Caetano, 2014).

Diante desse cenário, a forma mais adequada de tratamento desses resíduos é a técnica da compostagem, pois é considerada uma alternativa sustentável, simples, eficaz e que atende a legislação ambiental em vigor para a destinação final de resíduos orgânicos. Essa técnica consiste no processo de transformação de materiais grosseiros, como palhada e dejetos de animais, em materiais orgânicos estáveis que são utilizáveis na agricultura. Durante o processo de decomposição ocorre uma série de transformações complexas que envolvem reações bioquímicas, que são promovidas pelos milhões de microrganismos que utilizam a matéria orgânica como fonte de energia, nutrientes minerais e carbono (Vicentini et al. 2009). 
A utilização do processo de compostagem visa o aceleramento da decomposição do material orgânico, sendo necessária a ação dos microrganismos decompositores e condições ambientais favoráveis a um bom desenvolvimento e um menor tempo de estabilização destes resíduos. Os parâmetros físico-químicos que se destacam no desenvolvimento até a estabilização do processo de compostagem são a temperatura, aeração, umidade, $\mathrm{pH}$, além do controle inicial dos nutrientes, principalmente carbono e nitrogênio (relação $\mathrm{C}: \mathrm{N}$ ), tais fatores são essenciais para que os microrganismos encontrem as condições ideais para realizarem o seu papel (Caetano, 2014).

O período para a estabilização de materiais orgânicos sólidos em processo de compostagem é bem variável, podendo levar entre 30 e 60 dias, sendo necessários mais outros 30 a 60 dias para a completa humificação do composto. De acordo com Goes et al. (2017), os processos de compostagem podem ser intensificados com a adição de microrganismos eficientes. Em concordância, Bonfim et al. (2011) indicam sua utilização, principalmente, em compostos de decomposição natural lenta, principalmente, os que possuem alta relação $\mathrm{C} / \mathrm{N}$.

Conforme Caetano (2014), o emprego dos MEs no processo de compostagem, pode favorecer nos processos da degradação e estabilização da matéria orgânica, eliminando muitos microrganismos indesejáveis no processo de produção e algumas substâncias nocivas.

Em estudo utilizando doses de 1:250, 1:500 e 1:1000 de MEs nas compostagens de restos sólidos de piretro após a extração de piretrinas (bagaço), Mwegoha (2012), constatou reduções da relação C/N de 11: 1, 12: 1 e 15: 1 respectivamente, em um período de 34 dias de avaliação do processo de compostagem.

Caetano et al. (2020), em experimento com a adição de EM na decomposição de resíduos vegetais lignocelulósico de milho e soja em sistema de cultivo consorciado e cultivo solteiro, comprovaram que os tratamentos de restos culturais quando inoculados com microrganismos eficientes tendem a ter uma maior velocidade de decomposição em ambas as situações. Estudos realizados por Grazik (2020), avaliando a aplicação de microrganismos eficientes no processo de vermicompostagem em pequena escala, visando a eliminação de patógenos verificou-se que os tratamentos com a presença de EM tiveram maior papel de desempenho na redução de coliformes termotolerantes, a concentração de $8 \mathrm{ml} / \mathrm{L}$ apresentou resultados satisfatoriamente superior aos demais.

Vicentini et al. (2009), concluem que a adição de Microrganismos Eficientes no momento da formação de pilhas de compostagem, resulta em um menor tempo de preparo do composto, devido a maior atuação desses microrganismos, assim como no favorecimento para a reprodução de minhocas.

Nesse sentido, Pereira et al. (2014) ressaltam que os MEs "constituem uma alternativa eficaz, sustentável, segura e de baixo custo para aumentar a produtividade dos alimentos orgânicos, sendo sua utilização uma boa opção de manejo agroecológico". Os benefícios gerados a partir da inoculação dos MEs no processo de decomposição vão além da rapidez na estabilização dos resíduos, pois contribuem para o fornecimento e disponibilização de nutrientes e eliminação de microrganismos patogênicos, tornando os substratos propícios para a utilização nos sistemas de produção agrícola.

\subsection{Resíduos com potencial para utilização no processo de compostagem com a adição dos MEs}

A geração de resíduos oriundos da atividade agrícola e agropecuária é grande, variando de restos culturais, dejetos animais e resíduos agroindustriais. Tais resíduos demoram a se decompor naturalmente e podem provocar sérios problemas de poluição. Para Muscope (2017), os resíduos gerados no setor da agropecuária podem ser um dos principais problemas gerados para a degradação do meio ambiente, pois quando estes são descartados de maneira incorreta irão provocar a poluição do solo, das águas subterrâneas e do ar presente na atmosfera.

No entanto, tais resíduos apresentam alto potencial de utilização no processo de compostagem e produção de húmus, e assim podem ser reinseridos nos sistemas de produção agrícola. A compostagem surgiu como uma estratégia tecnológica, 
eficiente e de baixo custo, para tratar e aproveitar a matéria orgânica e os nutrientes oriundos dos resíduos, uma vez que este processo os transforma em composto orgânico humificado capaz de complementar a utilização de fertilizantes minerais, resultando em menor dependência de insumos importados, redução de custos de produção, melhorando as propriedades do solo (Máximo, 2018).

Dentre as limitações para sua adoção, está o tempo para a obtenção do composto orgânico final para utilização, deste modo, a adição de MEs tem sido amplamente difundida, uma vez que estes podem degradar diversos compostos orgânicos, reduzindo esse tempo e obtendo um composto que pode ser aplicado de forma segura ao solo (Máximo, 2018). Neste sentido, Grazik (2020) destaca que os MEs constituem em uma tecnologia sustentável, e que tem se mostrado viável no desenvolvimento dos processos de compostagem.

Deste modo, a literatura retrata alguns resultados de estudos acerca destes resíduos sólidos orgânicos que apresentam alto potencial para a produção de composto, e que podem ter seus processos intensificados com a adição dos microrganismos eficientes (Quadro 3).

Quadro 3. Resíduos com potencial para a produção de composto orgânico com a adição de microrganismos.

\begin{tabular}{|c|c|c|c|}
\hline Substrato & utor/Ano & 'ítulo & Resultados \\
\hline $\begin{array}{l}\text { Esterco bovino com } \\
\text { palha de cana-de-açúcar }\end{array}$ & $\begin{array}{l}\text { Caetano, } \\
2014 .\end{array}$ & $\begin{array}{l}\text { Micro-organismos Eficientes } \\
\text { (EM's) na compostagem de } \\
\text { palha de cana-de-açúcar e } \\
\text { esterco bovino }\end{array}$ & $\begin{array}{l}\text { A adição de MEs contribui para o melhoramento do } \\
\text { processo de compostagem. Melhores resultados de } \\
\text { redução de C/N e redução de peso, foram obtidos no } \\
\text { tratamento com } 100 \% \text { da concentração de MEs }\end{array}$ \\
\hline $\begin{array}{l}\text { Esterco bovino e ovino } \\
\text { com a adição de } \\
\text { serragem como fonte de } \\
\text { carbono. }\end{array}$ & $\begin{array}{l}\text { Muscope, } \\
2017 .\end{array}$ & $\begin{array}{l}\text { Compostagem de resíduos } \\
\text { agroindustriais através da } \\
\text { inoculação de microrganismos } \\
\text { eficientes: Uma alternativa para } \\
\text { a compostagem em pequena } \\
\text { escala }\end{array}$ & $\begin{array}{l}\text { A compostagem de esterco bovino e ovino em pequena } \\
\text { escala com o uso de MEs se mostrou bastante viável, } \\
\text { resultando em um composto final livre de contaminação } \\
\text { por patógenos. }\end{array}$ \\
\hline $\begin{array}{l}\text { Resíduos de soja e } \\
\text { milho }\end{array}$ & $\begin{array}{l}\text { Caetano, } \\
2020 .\end{array}$ & $\begin{array}{l}\text { Microrganismos eficientes na } \\
\text { decomposição de resíduos de } \\
\text { soja e milho }\end{array}$ & $\begin{array}{l}\text { A utilização de MEs pode alterar a velocidade de } \\
\text { decomposição de resíduos vegetais lignocelulósico. }\end{array}$ \\
\hline $\begin{array}{l}\text { Folhas secas e farelo de } \\
\text { arroz }\end{array}$ & $\begin{array}{l}\text { Fan, et al. } \\
2018 \text {. }\end{array}$ & $\begin{array}{l}\text { Evaluation of Effective } \\
\text { Microorganisms on Home Scale } \\
\text { Organic Waste Composting }\end{array}$ & $\begin{array}{l}\text { O composto com MEs mostrou alguns impactos } \\
\text { significativos, incluindo a melhoria do controle de odores } \\
\text { e alguns parâmetros (processo de humificação, redução } \\
\text { de gordura e teor de } \mathrm{N} \text { ). }\end{array}$ \\
\hline $\begin{array}{l}\text { Mistura de esterco } \\
\text { bovino, ovino e } \\
\text { serragem. }\end{array}$ & $\begin{array}{l}\text { Panisson, } \\
2017\end{array}$ & $\begin{array}{l}\text { Avaliação de diferentes } \\
\text { processos de compostagem em } \\
\text { pequena escala com adição de } \\
\text { microrganismos eficientes }\end{array}$ & $\begin{array}{l}\text { A adição de MEs influenciou mais na redução de } \\
\text { patógenos do que a temperatura ou o tipo de processo } \\
\text { empregado. Os MEs também são benéficos para o } \\
\text { aumento da concentração de nutrientes, além de } \\
\text { influenciar na redução de metais. }\end{array}$ \\
\hline $\begin{array}{l}\text { Pilhas de compostagem } \\
\text { composta por: plantas } \\
\text { de língua de vaca, } \\
\text { esterco bovino com } \\
\text { silagem, palhada, } \\
\text { esterco ovino com } \\
\text { cama, resíduos de } \\
\text { quintal e silagem }\end{array}$ & $\begin{array}{l}\text { Vicentini; } \\
\text { Carvalho \& } \\
\text { Richter, 2009. }\end{array}$ & $\begin{array}{l}\text { Utilização de Microorganismos } \\
\text { Eficazes no Preparo da } \\
\text { Compostagem }\end{array}$ & $\begin{array}{l}\text { A adição dos MEs nas pilhas de compostagem contribuiu } \\
\text { para o surgimento e reprodução das minhocas, além disso } \\
\text { as composteiras com MEs proporcionou } 90 \% \text { da } \\
\text { decomposição do esterco, enquanto nas que não foram } \\
\text { adicionados a decomposição foi apenas de } 25 \% \text {. }\end{array}$ \\
\hline $\begin{array}{l}\text { Resíduos de mistura de } \\
\text { estercos } \\
\text { (galinha, caprino e } \\
\text { ovino), Pennisetum } \\
\text { purpureum e palha seca } \\
\text { de milho }\end{array}$ & Grazik, 2020. & $\begin{array}{l}\text { Tratamento de resíduos } \\
\text { orgânicos agroindustriais por } \\
\text { vermicompostagem em pequena } \\
\text { escala }\end{array}$ & $\begin{array}{l}\text { O processo de vermicompostagem com a adição de MEs } \\
\text {, mostrou-se uma tecnologia eficiente para os resíduos } \\
\text { utilizados e resultou em um composto final de qualidade. } \\
\text { A adição de MEs ao processo mostrou-se uma tecnologia } \\
\text { eficiente na redução de patógenos, em que as maiores } \\
\text { reduções ocorreram no tratamento } 8 \mathrm{ml} / \mathrm{L} \text {. }\end{array}$ \\
\hline
\end{tabular}

Fonte: Autores (2021). 


\section{Conclusão}

Com base nos resultados encontrados nessa revisão, conclui-se que os Microrganismos Eficientes (ME) possuem uma ampla utilização e benefícios para o desenvolvimento sustentável da agricultura. Percebe-se também, que diversas pesquisas comprovam que o seu uso proporciona inúmeras vantagens no tratamento de resíduos através das técnicas de compostagem e vermicompostagem. Assim, os resíduos provenientes dos diversos setores produtivos poderiam ser reinseridos nos solos cultiváveis, como forma de melhoria das suas condições físico-químicas e biológicas, estando livres de contaminação microbiológica, metais pesados e outros elementos que possam causar degradação ao ambiente.

O Brasil tem potencial significativo, considerando a biodiversidade de microrganismos e produção de diferentes substratos, que podem ser testados visando à redução, estabilização e humificação dos mesmos para serem reinseridos no sistema de produção agrícola. Por se tratar de uma temática atual, é importante a investigação por meio de mais estudos que envolvam a categorização dos já referidos microrganismos, bem como as concentrações que podem ser aplicadas a cada finalidade de uso.

Dentre os resíduos com amplo potencial na produção de compostos podemos citar a utilização dos dejetos animais, produzidos nos setores da avicultura, suinocultura, bovinocultura e ovinocaprinocultura, que podem ser associados a outros resíduos agrícolas com a palhada de milho, soja, banana, café, cana-de açúcar, algodão e outros resíduos volumosos com é o caso da poda de árvores. Ou seja, um nicho significativo para prospecções de novas pesquisas.

Portanto, a utilização da tecnologia MEs é uma alternativa na melhoria da produção e das condições de cultivo, sendo inoculados no solo, nas plantas, no tratamento de sementes, e também no processo de decomposição de materiais por meio da técnica da compostagem, possibilitando aumento na qualidade e produtividade do solo e da colheita.

\section{Agradecimentos}

Os autores gostariam de agradecer à Pró-Reitoria de Pesquisa e Inovação que, por meio do Edital № 63 , de 08 de maio de 2020, Chamada Interna PROPES No 05/2020, concedeu a bolsa de Iniciação Científica.

\section{Referências}

Alami, S., Desjeux, D. \& Garabuau-Moussaoui, I. (2010). Os métodos qualitativos. Vozes.

Alvarez-Vera, M. S., et al. (2019). Obtenção de consórcios microbianos benéficos e sua incidência na población microbiana nativa da rizósfera de plantas de fresa (Fragaria sp.), Polo del conocimiento. 4(11), 149-179.

Andrade, F. M. C. (2020). Caderno Dos Microrganismos Eficientes (E.M.): Instruções práticas sobre uso ecológico e social do EM. Universidade Federal de Viçosa/Departamento de Fitotecnia. (3a ed.). 31 p.

Avila, G. M. A., et al. (2021). Use of efficient microorganisms in agriculture. Research, So-ciety and Development, 10(8), 1-13.

Bonfim, F. P. G., et al. (2011). Caderno Dos Microrganismos Eficientes (EM): Instruções práticas sobre uso ecológico e social do EM. Universidade Federal de Viçosa/Departamento de Fitotecnia. (2a ed.). 32 p.

Caetano, L. A., et al. (2020). Microrganismos eficientes na decomposição de resíduos de soja e milho. Anais do XI Congresso Brasileiro de Agroecologia, São Cristóvão, 15(2).

Caetano, M. I. (2014). Micro-organismos eficientes (EM’s) na compostagem de palha de cana-de-açúcar e esterco bovino. 2014.70 p. Trabalho de Conclusão de Curso (Graduação em Engenharia Ambiental) - Universidade Tecnológica Federal do Paraná, Londrina, PR.

Calero-Hurtado, A., et al. (2019). Efecto entre microorganismos eficientes y fitomas-e en el incremento agroproductivo del frijol. Biotecnología en el Sector Agropecua-rio y Agroindustrial, 17(1), 25-33.

Cargnelutti, D., et al. (2021). Soluções tecnológicas emergentes para uma agricultura sustentável: microrganismos eficientes. In: García, L. M. H. Agroecologia: princípios e fundamentos ecológicos aplicados na busca de uma produção sustentável, Canoas: Mérida Publishers, $31-62$.

Conceição, V., et al. (2012). Coquetel biológico (EM) no crescimento de mudas de Ocimum basilicum L. Cadernos de Agroecologia, 7(2).

Dourado, E. R. (2018). Microrganismos eficientes (EM) no tratamento de sementes de milho. 2018. 62 p. Dissertação (Mestrado em Agroecologia) Universidade Federal de Viçosa. 
Fan, Y. V., et al. (2018). Evaluation of Effective Microorganisms on home scale organic waste composting. Journal of Environmental Management, 216, 4148 .

Gil, A. C. (2002). Como elaborar projetos de pesquisa. Atlas.

Gil, A. C. (2010). Como elaborar projetos de pesquisa. (5a ed.), Atlas.

Goes, H. H. D., et al. (2017). Compostagem de resíduo agroindustrial e poda de árvore com aplicação de microrganismos eficientes. Anais do $8^{o}$ Fórum Internacional de Resíduos Sólidos.

Grazik, H. A. (2020). Tratamento de resíduos orgânicos agroindustriais por vermi-compostagem em pequena escala. 2020. 2020.48 p. Trabalho de Conclusão de Curso (Graduação em Engenharia Ambiental e Sanitária) - Universidade Federal da Fronteira Sul Campus de Erechim, Erechim, RS.

Higa, T. \& Parr, J. F. (2013). Microorganismos Benéficos y efectivos para una agricultura y medio ambiente sostenibles. Maryland (USA): Centro internacional de Investigación de Agricultura Natural, Departamento de Agricultura de los Estados Unidos, v. 13.

Lüdke, M. \& André, M. (2015). Pesquisa em educação: abordagens qualitativas. (2a ed.), E.P.U.

Mares Guia, A. P. O. Produtividade de milho verde cultivado em sucessão a adubação verde com aplicação de microrganismos eficientes, nas condições de Matias Barbosa, MG. 2018. 63 p. Dissertação (Mestrado em agricultura orgânica) -Universidade Federal Rural do Rio de Janeiro, Seropédica, RJ, 2018.

Máximo, K. A. (2018). Inoculação de microrganismos como aceleradores no processo de compostagem de resíduos sólidos agroindustriais. 2018.165 p. Dissertação (Mestrado em Sustentabilidade e Tecnologia Ambiental) - Instituto Federal de Educação, Ciência e Tecnologia de Minas Gerais Campus Bambuí, Bambuí, MG.

Minayo, M. C. S. (2012). Análise qualitativa: teoria, passos e fidedignidade. Ciênc. saúde coletiva, 17(3), 621-626.

Minayo, M. C. S. \& Sanches, O. (1993). Quantitativo-Qualitativo: oposição ou complementaridade? Caderno de Saúde Pública, 9(3), $239-262$.

Muscope, F. P. (2017). Compostagem de resíduos agroindustriais através da inoculação de microrganismos eficientes: uma alternativa para a compostagem em pequena escala. 2017. 46 p. Trabalho de conclusão de curso (Graduação em Engenharia Ambiental) - Universidade Federal da Fronteira Sul Campus de Erechim, Erechim, RS.

Mussi, R. F. F., et al. (2019). Pesquisa Quantitativa e/ou Qualitativa: distanciamentos, aproximações e possibilidades. Revista Sustinere, $7(2), 414$ - 430

Mwegoha, W. (2012). Anaerobic composting of pyrethrum waste with and without effective microorganisms. African Journal of Environmental Science and Technology, 6(8), 293-299.

Panisson, R. (2018). Avaliação de diferentes processos de compostagem em peque-na escala com adição de microrganismos eficientes. 2017. 52 p. Dissertação (Mestrado em Ciência e Tecnologia Ambiental) - Universidade Federal da Fronteira Sul Campus de Erechim, Erechim, RS.

Pedrosa, M. V., et al. (2015). Importância ecológica dos microrganismos do solo. Enciclopédia Biosfera, Centro Científico Conhecer. 11(22), 100 p.

Pereira, T. G., et al. (2014). Utilização de microrganismos eficientes (EM) na produção de alimentos orgânicos. VII Semana de Ciência e Tecnologia do IFMG-Campus Bambuí.

Pugas, A. S., et al. (2013). Efeito dos Microrganismos Eficientes na taxa germinação e no crescimento da Abobrinha (Curcubita Pepo L.). Cadernos de Agroecologia, 8, 1-5.

Silva, J., et al. (2020). Produção de pimentão em ambiente protegido sob diferentes concentrações de microrganismos eficientes. Enciclopédia Biosfera, $17(34)$.

Sousa, W. S., Pontes, J. R. V. \& Melo, O. F. P. (2020). Efficient Microorganisms in lettuce cultivation. Revista Agrogeoambiental, 12(2).

Vicentini, L. S., Carvalho, K. \& Richter, A. S. (2009). Utilização de microrganismos eficazes no preparo da compostagem. Faculdade Integrada Espirita. Revista Brasil Agroecologia. 4(2). 